\title{
Godofredo Rangel leitor: memórias literárias na correspondência trocada com Monteiro Lobato
}

\author{
Camila Russo de Almeida Spagnoli
}

\begin{abstract}
RESUMO: Com base na correspondência trocada entre Godofredo Rangel e Monteiro Lobato, reunida em A barca de Gleyre e no Suplemento Literário de Minas Gerais, o artigo recupera algumas das principais referências a autores e obras, estabelecendo possíveis diálogos entre essas memórias literárias e a obra de Rangel.
\end{abstract}

PALAVRAS-CHAVE: Godofredo Rangel; Monteiro Lobato; Suplemento Literário de Minas Gerais; A barca de Gleyre; Epistolografia.

ABSTRACT: Through the correspondence exchanged between Godofredo Rangel and Monteiro Lobato, gathered in A barca de Gleyre and in the Suplemento Literário de Minas Gerais, the article recovers some of the main references to authors and works, stablishing possible dialogues between these literary memories and the work of Rangel.

KEYWORDS: Godofredo Rangel; Monteiro Lobato; Suplemento Literário de Minas Gerais; A barca de Gleyre; Epistolography. 
Acabei de ordenar mais ou menos tuas cartas. Fazem um pacote de uns dois quilos. Impressos, dariam uns cinco volumes à Charpentier. Cá estão ao teu dispor. Foi meu compêndio de estética. Você e o Ricardo foram os meus dois iniciadores, você

tem continuado o que ele encetou, arrancando-me da mão romances de fancaria e orientando-me o gosto pela boa leitura.

Tuas cartas são um curso completo. Godofredo Rangel ${ }^{1}$

Os escritores José Godofredo de Moura Rangel (1884-1951) e José Bento Monteiro Lobato (1882-1948) partilhavam sua paixão pela literatura. Leitores privilegiados, opinavam sobre leituras, escritores e personalidades da época, ao mesmo tempo que compartilhavam seus textos e comentavam a criação. É o que registra o conjunto de cartas reunidas sob o título A barca de Gleyre, livro que Lobato organizou e publicou pela Companhia Editora Nacional em $1944 .{ }^{2}$ A obra congrega, contudo, somente a correspondência ativa endereçada ao amigo Godofredo Rangel. Cobre o período 1903-1948, sendo o primeiro um bilhete sem data, dado como de 1903, e o último, uma carta de 23 de junho de 1948, doze dias antes da morte do remetente.

Diversas e indefinidas são as hipóteses para a não publicação das respostas do interlocutor lobatiano. Protegidas pelo direito à intimidade, as cartas são documentos sigilosos, como destaca Marcos Antonio de Moraes, ${ }^{3}$ tendo seu acesso, consulta e publicação condicionados às autorizações do remetente e do destinatário, bem como de qualquer pessoa citada no documento, e, na ausência deles, de seus herdeiros legais. No caso das cartas de Godofredo Rangel, o responsável por conservar a correspondência em pastas, juntamente com os documentos restantes do acervo, é Márcio Sampaio, viúvo de Eliana Rangel, neta do escritor. Em 1984, foi ele quem organizou dois números especiais

1. Sampaio, Márcio (org.). “Godofredo Rangel/Monteiro Lobato: 40 anos de correspondência”. Suplemento Literário de Minas Gerais, Belo Horizonte, ano 19, n. 948, $1^{\circ}$ dez. 1984, p. 10. Carta de 15 out. 1916.

2. Utilizamos a edição: LOBAтo, Monteiro. A barca de Gleyre. Edição de Arlete Alonso (coordenação), Cecília Bassarani e Luciane Ortiz de Castro. Consultoria e pesquisa: Márcia Camargos e Vladimir Sacchetta. São Paulo: Globo, 2010.

3. MORAes, Marcos Antonio de. "Ligações perigosas". In: PINo, Claudia Amigo (org.). Criação em debate. São Paulo: Humanitas, 2007, p. 67. 
do Suplemento Literário de Minas Gerais (SLMG), ${ }^{4}$ no qual dezessete cartas, até então inéditas, escritas por Rangel e endereçadas a Lobato, estão publicadas. Embora Sampaio não revele os critérios empregados para a seleção e a edição dessa parcela de missivas, no texto introdutório "A outra Barca", assinala a presença dos herdeiros na escolha "daquilo que lhes parece literariamente relevante", conforme vontade expressa do autor.

Em linhas gerais, a correspondência disponibilizada no $S L M G$ recobre o período 1905-1945, diferindo do recorte apresentado em A barca de Gleyre. Resgata fragmentos do cotidiano de Rangel: a época dos exames finais (quando ainda era estudante), recordações dos antigos amigos, a dedicação aos diversos ofícios, a vida atribulada em contraste com o marasmo da roça etc. Acompanham-se também as discussões diante dos mais diversos temas: passagem do tempo, doenças, morte, artes, literatura, além de rastros e etapas do processo de criação e da própria preparação das cartas para a publicação.

A multiplicidade de referências literárias, deixadas em A barca de Gleyre, motiva diferentes trabalhos, principalmente como fonte de estudo da obra e da vida de Monteiro Lobato. Consegue-se, por meio da leitura da correspondência, passear pela biblioteca lobatiana, seja ela virtual e hipotética ou apenas fragmentos daquilo que foi outrora. Autores, obras, concepções estéticas, exercícios literários, em meio a tantas outras abordagens feitas à literatura, são assuntos extensivamente debatidos nos mais de quarenta anos de conversa epistolar. ${ }^{5}$

Desdobrando-se na trajetória de juiz, escritor, tradutor e professor, os caminhos de Godofredo Rangel também transitam pela literatura. Desconhecidos são os rumos

\footnotetext{
4. Márcio Sampaio organizou duas edições especiais do Suplemento Literário de Minas dedicadas a Godofredo Rangel, como forma de prestar uma homenagem ao escritor no ano de seu centenário. O primeiro número data de 24 de novembro e o segundo de $1^{\circ}$ de dezembro, ambos de 1984: SAMPAIO, Márcio (org.). Suplemento Literário de Minas Gerais, Belo Horizonte, ano 19, n. 947, 24 nov. 1984; ano 19, n. 948, $1^{\circ}$ dez. 1984. Encontram-se digitalizadas as edições do Suplemento Literário de Minas Gerais. Disponíveis em: <http:// www.cultura.mg.gov.br/a-secretaria/consulta-publica-2/suplemento-literario>. Acesso: 10 de maio 2018. 5. As inúmeras referências literárias presentes em $A$ barca de Gleyre motivaram minha pesquisa de mestrado, "Monteiro Lobato, o leitor", cujo objetivo era recuperar parte das menções a leituras feitas pelo escritor, por meio das diversas citações a autores e obras. Além disso, reuni informações acerca dos títulos que estiveram nas estantes da biblioteca lobatiana e ainda permanecem no acervo do escritor na Biblioteca Infantil Monteiro Lobato (sp) no Fundo Monteiro Lobato, no Cedae/IEL (Unicamp). Cf. SPAGNOLI, Camila Russo de Almeida. "Monteiro Lobato, o leitor”. Dissertação (Mestrado em Filosofia) Instituto de Estudos Brasileiros, Universidade de São Paulo, São Paulo, 2014.
} 
de sua biblioteca pessoal, quiçá destruída junto à parte do espólio do escritor. ${ }^{6}$ É na correspondência com Lobato que, em meio às discussões sobre os mais variados temas, se testemunham momentos de formação e percurso literário, projetos de trabalho, gênese (muitas vezes compartilhada) e diversas etapas do preparo de obras e, principalmente, trocas de percepções de ordem literária.

O grande desafio é pensar no Rangel que, mesmo ausente na coletânea, manifesta-se em cada uma das missivas. Isto é, enseja-se a reconstrução, ainda que fragmentada e conjecturada conforme as reações do ponto de vista lobatiano, da identidade de Rangel, ou melhor, de sua imagem no conjunto epistolar, por meio das inflexões de sua voz em A barca de Gleyre. É nas cartas estampadas no Suplemento Literário que escutamos, mesmo parcialmente, a voz em geral silenciada de Godofredo Rangel. Apesar do volume de mensagens ser limitado, há alguns diálogos que se instauram entre os interlocutores.

Diante disso, a partir da correspondência restante em A barca de Gleyre e no Suplemento Literário de Minas Gerais, foram selecionados alguns trechos nos quais se buscou reconhecer vestígios do perfil de Rangel leitor e estabelecer possíveis diálogos entre algumas dessas memórias de leituras e a obra do escritor. Não se pode perder de vista a presença de Monteiro Lobato, não só enquanto interlocutor, mas como organizador e editor das cartas, projetando suas memórias e, consequentemente, as de seu amigo. E, embora o trabalho se concentre na figura de Rangel, seria impossível desconsiderar ou não se referir a Lobato em todo esse processo.

\section{AMIZADES LITERÁRIAS}

As primeiras incursões de Godofredo Rangel pelas letras são registradas por Enéas Athanázio. ${ }^{7} \mathrm{Na}$ infância, o mineiro teria integrado grupos teatrais amadores, inclusive assinando a autoria de algumas peças. Dedicou-se também à escrita de pequenos jornais manuscritos cujas seções eram todas preparadas por ele - artigos, noticiários, páginas literárias etc. É nessa época que parece ter se despertado seu interesse pelo estudo da língua portuguesa, aventurando-se na tentativa de decorar todo um dicionário, leitura retomada anos mais tarde.

6. sampaio, Márcio. “A outra Barca”. Suplemento Literário de Minas Gerais, Belo Horizonte, ano 19, n. $948,1^{\circ}$ dez. 1984 , p. 8.

7. athanázio, Enéas. Godofredo Rangel. Curitiba: Gráfica Editora 73, 1977, p. 16. 
Recordado na epígrafe que abre este trabalho, o amigo Ricardo Gonçalves (1883-1916), um dos "iniciadores" de Rangel, ao lado de Monteiro Lobato, deixa sua presença nas escolhas literárias do companheiro, durante o período de estudante de Direito, no Largo de São Francisco. Entusiasmado pelas obras de Escrich, Júlio Verne, Alexandre Dumas, Ponson du Terrail e Montépin, o jovem leitor ampliaria seu percurso de leituras após conhecer Ricardo. Edgard Cavalheiro ${ }^{8}$ conta que, no primeiro encontro, Ricardo surpreendeu-se ao deparar com Rangel debruçado sobre um desses autores de fancaria, tão interessado e "perdendo tempo com aquela droga". Assim, teria aconselhado "coisas de mais valor" e, na primeira visita que recebeu do novo amigo, presenteou-lhe com um exemplar de Germinal, de Émile Zola.

Por intermédio de Ricardo Gonçalves, Rangel conhecera Monteiro Lobato e, com outros companheiros, formaram o grupo autodenominado Cenáculo. Os jovens reuniam-se quase todas as noites no Café Guarani, à rua 15 de Novembro, e na república intitulada por eles de Minarete, chalé no Belenzinho, à rua 21 de Abril, onde os três amigos chegaram a morar juntos por alguns meses. ${ }^{9}$

É Lobato que, em 1903, intima Rangel a ingressar no universo das cartas. A chegada de uma nova missiva o entusiasma por lhe assegurar o diálogo com alguém cujas ideias são compatíveis com as suas: "Tua carta veio como aragem. Eu estava com saudades dum voo e aqui não há asas - só se discutem coronéis políticos e namoros. [...] Tuas cartas me são um estimulante; obrigam-me a pensar, abrem-me perspectivas". ${ }^{10}$

Alçam voo pela literatura! Percorrem desde clássicos da literatura universal a escritores brasileiros ainda inéditos em livro. Interessam-se por textos literários, críticos, verbetes, discursos... até mesmo um tratado sobre a criação de galinhas! ${ }^{11}$ Entre os frequentes, eventuais "formadores", podem-se assinalar, comentados, obras e estilos de romancistas como Anatole

8. CAVAlHeiro, Edgard. Monteiro Lobato: vida e obra. São Paulo: Companhia Editora Nacional, 1955, pp. 78-9.

9. Cf. azevedo, Carmen Lúcia de; Camargos, Márcia; sacchetta, Vladimir. Monteiro Lobato: furacão na Botocúndia. São Paulo: Senac, 1997, p. 41.

10. Lовато, Monteiro. Op. cit., p. 55. Carta de Taubaté, 20 jan. 1904.

11. Em meio à vida da Fazenda, Lobato escreve em 19 de agosto de 1912: "Ontem, a Galinocultura de Delgado de Carvalho me enlevou a cabeça e a alma, como outrora as enlevava um romance de Daudet". Em sua tese de doutorado, Armando João Dalla Costa afirma que o Tratado de galinocultura, de Delgado de Carvalho, avicultor e autor de diversas publicações, estava entre os mais lidos na época. Cf. DALlA COSTA, Armando João. Agroindústria brasileira contemporânea: Inovações organizacionais e transformações tecnológicas na avicultura. Tese de Doutorado, Université de la Sorbonne Nouvelle Paris III. Paris, França, 1997, p. 6o. Disponível em: <http://www.empresas.ufpr.br/teseajd.pdf>. Acesso: 28 de março de 2018. 
France, Gustave Flaubert, Honoré de Balzac, Alphonse Daudet, Guy de Maupassant, Rudyard Kipling, Nietzsche, Émile Zola, Camilo Castelo Branco, Machado de Assis, entre tantos outros. No entanto, há nomes raros na epistolografia, mencionados apenas de passagem.

Nota-se que as trocas literárias eram também estabelecidas no âmbito material. As cartas demonstram a prática dos epistológrafos de emprestarem livros que, inclusive, pertenciam às estantes de outros amigos, como exemplifica Lobato: "Informa-me com segurança de que sabes do Livro da jângal pertencente ao Albino, que reclama a berros. Anda aí?". ${ }^{12}$ Aliás, Lobato reclama da falta de cuidado de seu interlocutor com os títulos emprestados, que chegaram como "veteranos vindos duma guerra estropiadora", quando deveriam vir "como turistas que voltam duma viagem de recreio". ${ }^{13}$

Principalmente nos primeiros anos do conjunto epistolar, testemunham-se etapas do desenvolvimento de Rangel e Lobato enquanto leitores apurados e escritores em formação: sugestões e discussões sobre inúmeros autores e obras, preferências estéticas e estilísticas, exercícios de construção e aprimoramento expressivo, compartilhamento de manuscritos e de etapas do processo de criação. Tendo essas questões como ponto de partida, optou-se por concentrar o presente artigo no recorte temporal até 1920, ano em que Godofredo Rangel estreia em livro com Vida ociosa, e ambos os missivistas já estão lançados no mercado editorial. ${ }^{14}$

\section{VELHOS AMIGOS FRANCESES ${ }^{15}$}

Última leitura: Pequenos poemas em prosa, de Baudelaire. Livro para se ler aos quarenta anos, depois de embotados, apáticos, para se obter mais um estremeção nos nervos. Godofredo Rangel ${ }^{16}$

Ao rastrear as referências de leituras em A barca de Gleyre, percebe-se que há, até 1910, o predomínio de citações de autores e obras relacionadas ao universo da littérature

\footnotetext{
12. Lовато, Monteiro. Op. cit., p. 164. Carta de Areias, 22 set. 1907.

13. Idem, pp. 204-5. Carta de Areias, 6 jul. 1909.

14. Monteiro Lobato estreia em livro com Urupês, em 1918, esgotando sucessivas tiragens.

15. Referência ao modo como Rangel se reporta a escritores que ele e Lobato leram na época do Minarete. SAMPAio, Márcio (org.). “Godofredo Rangel/Monteiro Lobato: 40 anos de correspondência”. Suplemento Literário de Minas Gerais, cit., p. 10. Carta de Belo Horizonte, 8 set. 1946.

16. Idem, p. 10. Carta de Três Pontas, 16 nov. 1919.
} 
française, enfatizando o papel da cultura francesa (de modo especial, da literatura) em seu diálogo com o Brasil nos primeiros decênios do século xx. Se o período 1903-1918 é considerado o mais intenso da amizade escrita entre Godofredo Rangel e Monteiro Lobato, logo a presença francófona nas cartas deixa pistas de sua posição de destaque na formação de ambos os escritores ${ }^{17}$, sabendo-se que nenhum dos dois visitou a França, nem há qualquer registro de amizade ou correspondência com franceses. ${ }^{18}$

A carta de 22 de setembro de 1907 é exemplar para discutir a forma como menções à literatura, indicações de leituras e comentários críticos se apresentam na correspondência. A citação reúne crítica de Lobato e revela leitores intelectualmente envolvidos com a produção literária francesa:

De um ano para cá tenho acompanhado o movimento literário da França de hoje e me parece que não decai do anterior - tão nosso conhecido, com Zola, Daudet, Goncourt, Flaubert; e hoje te mando um volume do Tristan Bernard, pequena obra-prima de psicologia espirituosa, com muitas semelhanças com teu estilo e alguns personagens evidentemente furtados dos teus borrões. Nascido em França, serias o próprio Tristan Bernard. Lê e julga. ${ }^{19}$

Entre os citados, Alphonse Daudet é registro frequente entre os missivistas. Godofredo Rangel chega a compor um hino para recepcionar os amigos no Minarete, remetendo ao grito de guerra dos tarasconeses de Port-Tarascon:

17. Cabe notar que a relação com a França, registrada em A barca de Gleyre, não procede unicamente da literatura, pois se verificam referências a personagens históricas, como Luís Xvi, Robespierre, Napoleão etc. Assinalam-se inúmeros vocábulos e expressões em francês nas cartas, inclusive trechos em que frases inteiras são transcritas.

18. É interessante perceber que, afora o contato com a cultura e, sobretudo, com a literatura gálica, o domínio da língua francesa permitia a Rangel e Lobato o acesso a outras literaturas estrangeiras. É o caso das versões em francês que tornaram acessíveis poetas, romancistas e filósofos, nomes como Goethe, Byron ou Hegel, e difundiram o romance russo a partir de 188o. Observa-se que o mesmo ocorre com os textos de Nietzsche, informação dada pelo próprio Lobato: “[...] Chegou-me o Nietzsche em dez preciosas brochuras amarelas, tradução de Henri Albert” (Carta de São Paulo, 2 jun. 1904). Há ainda outros autores lidos em traduções francesas, como Homero: "Sabe de alguma tradução de Homero em português? Leio na de Lecomte" (Carta de Areias, 3 fev. 1908). Isto é, na versão assinada pelo poeta francês Lecomte de Lisle, tradutor de Homero e Ésquilo.

19. LOBAto, Monteiro. Op. cit., p. 163 e 164. Carta de Areias, 22 set. 1907.

Teresa revista de Literatura Brasileira [19]; São Paulo, 2018 • 255 
Versão: Port-Tarascon

Dé brin o dé bran

Cabussaran

Dou fenestroun

De Tarascoun

Dedins lou Rose

\section{Versão: Hino do Minarete}

Dé brin o dé bran

Cabússaran

Dou fenestron

De Minaron

Dedins lou Tetiose

Imbuídos do Tartarin, os companheiros se faziam personagens da história. Ricardo era o herói que deu nome à narrativa. Rangel, Bezuquet. Cândido Negreiros, Bompard. Artur Ramos, o espingardeiro Costecalde. Lobato, Pascalon, o Engraçado. ${ }^{20} \mathrm{Na}$ carta de $1903^{21}$ remete-se a Rangel como Bezuquet. Ainda impregnado por Daudet, Lobato, em algumas cartas, tomou emprestados elementos do romance. $\mathrm{O}$ bilhete que abre a seleção de A barca de Gleyre inicia-se com a saudação "Té, muezins!" e termina com “Té, Bezuquet! Vé, Tartarin!".

Daudet não é o único estimado na literatura francesa. A obra de Gustave Flaubert divide a opinião dos missivistas. A leitura desagrada e "maça seriamente" ${ }^{22}$ a Lobato, que adverte o amigo: "Sare, homem! Estás malíssimo de ingurgitamento literário. Vomite o Flaubert!"”23 Entretanto, a forte assimilação de Godofredo Rangel pela escrita do autor de Léducation sentimentale é novamente criticada após a publicação do conto "Gouache", no Minarete:24

O teu "Gouache" do último Minarete (o prodigioso revisor do Benjamin deixou sair "Gonache", palavra sem significação que deve estar dando dor de cabeça nos pindamonhangabanos), e teu "Gonache" é uma pura imitação pastichada desse Flaubert que te anda estragando as tripas do estilo. Entre a maneira de Flaubert e a de Rangel a diferença é nula - o que seria ótimo para você, se você houvesse vindo ao mundo antes de Flaubert. ${ }^{25}$

20. Idem, p. 35. Nota de Monteiro Lobato.

21. Idem, p. 44. Carta de São Paulo, 1903 (sem data completa).

22. Idem, p. 85. Carta de Taubaté, 2 fev. 1905.

23. Idem, p. 54. Carta de São Paulo, 10 jan. 1904.

24. Jornal este que circulou em Pindamonhangaba/SP, mantido por Benjamin Pinheiro, de julho de 1903 a julho de 1907. Tanto Godofredo Rangel quanto Monteiro Lobato colaboraram com textos.

25. Lовато, Monteiro. Op. cit., p. 85. Carta de Taubaté, 2 fev. 1905. 
Explorar diferentes padrões estético-estilísticos, como parte da formação de ambos os escritores, é tarefa prezada por Lobato. O magister do Cenáculo, epíteto de Lobato que os amigos usaram e ele próprio chegou a utilizar, ${ }^{26}$ não economiza nas censuras. Embora insista para que Rangel se distancie do estilo "secante", ${ }^{27}$ nota a persistência e prescreve a leitura de Anatole France, a fim de que seu interlocutor se cure da "flaubertite crônica”. A brincadeira e o tom humorístico caracterizam o estilo lobatiano, assim como o discurso pedagógico e "catequizador": "Por que não afundas em Anatole, Rangel? Sabe que isso já está me revoltando - essa demora em entrares no bom porto?". ${ }^{28}$ Logo, "para começo da catequese", indica Crainquebille, Putois, Histoire comique, Lorme du mail, La rôtisserie de la reine Pédauque e o Abbé Coignard - Les Opinions de M. Jérome Coignard.

São recorrentes também, no tempo do Minarete, as referências a Émile Zola, citados na correspondência os títulos Germinal, Lassommoir, La joie de vivre, Le rêve e Le docteur Pascal - da série Les Rougon-Macquart -, assim como Travail e Mes heines.

Apesar do pouco número de cartas disponibilizadas no SLMG, acompanha-se um breve debate em torno da estética naturalista. Sabe-se que Zola, entusiasmado com as pesquisas do fisiologista francês Claude Bernard, no campo teórico-prático da medicina, procura adaptar, de maneira literal, os métodos científicos à literatura, na medida em que vê esta como que determinada pelas ciências. ${ }^{29}$ Em carta de 2 de fevereiro de 1905, Lobato admite não compreender a relação entre ciência e arte e conclui: "misturar estas coisas é tentar a combinação química de ovos e batatas". ${ }^{30}$

A discussão é retomada, oito dias depois, com a chegada da resposta de Godofredo Rangel que, assim como Lobato, critica a premissa de que a arte baseada na ciência seja verdadeira, contrariando o rigor metodológico de Zola em aproximar a arte da objetividade científica:

Disseste na tua última que não compreendias que relação havia entre arte e ciência, e nem por que eu te perguntava se a arte deve ser sempre científica. Achas isso um absurdo. Eu

\footnotetext{
26. Termo utilizado em: Idem, Carta de Taubaté, 20 jan. 1904; Carta de São Paulo, 2 jun. 1904.

27. Idem, p. 95. Carta de Taubaté, 19 ago. 1905.

28. Idem, p. 140. Carta de Areias, 21 jan. 1907.

29. Gomes, Álvaro Cardoso. "O diálogo entre a literatura e as ciências: o romance experimental de Zola”. Graphos, João Pessoa, vol. 8, n. 1, p. 107, jan./jul. 2006.

30. Lobato, Monteiro. Op. cit., p. 85. Carta de Taubaté, 2 fev. 1905.
} 
também. Fiz-te a pergunta porque em milhares de crônicas teratológicas tenho lido isso. Eu acho também que ciência é ciência e arte é arte.

Por isso é que reprovo quando Zola diz a verdade na arte... La verité, porque la verité... Ora, esta expressão tanto tem de pedante como de falsa. $\mathrm{Na}$ arte absolutamente não se cogita da verdade, dessa abstração mental, e apenas da fidelidade..$^{31}$

Na carta de 28 de janeiro, 1907, também registrada no SLMG, avançam as desaprovações de Rangel ao precursor do naturalismo, especificamente ao método do romance experimental e à redução das personagens aos mecanismos de repetição:

Ora, o Zola um gênio! Tu me escandalizaste! Um homem de que todos os personagens se repetem, infalivelmente, repetindo-se como macacos o modo de falar, de sentir, de gesticular, de sonhar! Abre qualquer de seus romances, e lá verás sempre a mesma paixão épica, cega, obcecante, aprumando-se sempre para a mesma direção, tomada de um fatalismo irresistível, que a gente, lendo, fica adivinhando o decurso da obra toda. Um horror, uma máquina de repetição. ${ }^{32}$

Apesar das críticas que faz ao movimento, anos mais tarde Lobato admite o papel das leituras zolaianas na formação deles: "Um defeito meu, teu, nosso: damos espaço demais ao cenário, com prejuízo das figuras [...]. Nós nos perdemos nas mignardises da paisagem, a copiar até as perninhas dos carrapatos - vício que vem do tempo em que o naturalismo zolaiesco nos seduziu". 33

Cabe notar que o comentário lobatiano, ao apontar como "defeito" de ambos excederem-se nas descrições do espaço, parece antecipar, em certa medida, a crítica de Antonio Candido, registrada no prefácio de Falange gloriosa (1955). Nela, o prefaciador descreve a maneira literária de Godofredo Rangel como caligráfica: ela se assemelharia à de um grupo de calígrafos que, sensíveis à beleza formal da página, trariam à escrita uma aplicação minuciosa. ${ }^{34}$ Aponta como pecado da literatura caligráfica, inclusive na obra de

\footnotetext{
31. Sampaio, Márcio (org.). Op. cit., p. 9. Carta de São Paulo, 10 fev. 1905.

32. Idem. Carta de 28 jan. 1907.

33. Lовато, Monteiro. Op. cit., p. 301. Carta da Fazenda, 30 jan. 1915.

34. CANDido, Antonio. "Literatura caligráfica". In: RANGEL, Godofredo. Falange gloriosa. São Paulo: Melhoramentos, [1955]. Prefácio, p. 4.
} 
Rangel, a tendência ao rebuscamento e a frouxidão na economia do livro, caracterizada pela não subordinação a uma linha definida de composição, de modo que:

propicia aquelas digressões em que o autor, dispersando-se, concentra-se em cada cena, cada episódio, cada diálogo, como se fossem autônomas, desligadas do contexto. Em escritor doutra índole, ou menos pulso, esta composição lassa poderia levar ao desalinho da forma e à confusão do assunto. No calígrafo, leva sobretudo a certa miopia novelesca, ao desconhecimento da estrutura em benefício dos pormenores, que avultam deste modo como pretexto de um lavor caprichoso e aturado. ${ }^{35}$

Inúmeras referências a escritores franceses estão registradas na correspondência. Poetas, ficcionistas, teatrólogos, ensaístas... a lista é extensa e variada. Devido aos limites de extensão deste trabalho, não é possível estudar cada um desses escritores na relação que têm com a formação de Godofredo Rangel e sua produção literária, o que exigiria uma série de análises. ${ }^{36}$

\section{EM BUSCA DE ESTILO E EXPRESSÃO}

Ando com saudades da literatura e das piabas do Machado. O que de melhor li aqui foi o Gervásio Lobato, engraçadíssimo autor português, que deves conhecer.

Godofredo Rangel ${ }^{37}$

\section{Idem, p. 7 .}

36. É preciso destacar que não passam despercebidas as menções a outras literaturas, que motivaram estudos como o da pesquisadora Raquel Nunes Endalécio sobre a relação de Lobato com escritores gregos, o de Ana Luiza Reis Bedê, que focalizou a presença da França nas cartas, e o de Lucila Bassan Zorzato sobre as referências alemãs.

Cf. ENDAlÉcio, Raquel Nunes. A (re)construção do mundo clássico na obra de Monteiro Lobato: fontes e procedimentos. 176 p. Dissertação (Mestrado em Filosofia) - Instituto de Estudos Brasileiros, Universidade de São Paulo. São Paulo, 2013.

BEDÊ, Ana Luiza Reis. Monteiro Lobato e a presença francesa em A barca de Gleyre. São Paulo: Annablume/ Fapesp, 2007.

zorzato, Lucila Bassan. "A Alemanha em Lobato". Anais da X Semana de Letras. 70 Anos: A Fale Fala. Anais X Semana de Letras. Porto Alegre: EDIPUCRs, 2010. Disponível em: <http://ebooks.pucrs.br/edipucrs/ anais/Xsemanadeletras/comunicacoes/Lucila-Bassan-Zorzato.pdf $>$. Acesso: 15 de agosto de 2018.

37. SAmpaio, Márcio(org.). “GodofredoRangel/MonteiroLobato:40anos decorrespondência”.Suplemento Literário de Minas Gerais, cit., p. 9. Carta de Campinas, 1912. 
Por volta de 1909, a literatura portuguesa passa a ganhar espaço no jogo epistolar, sendo Camilo Castelo Branco o escritor mais citado nas cartas do período. Contudo, desde 1903, diferentes autores portugueses aparecem nas páginas d'A barca; alguns apenas uma vez, outros com mais referências. Desse modo, encontram-se: Eça de Queirós, Alexandre Herculano, Oliveira Martins, Luís de Camões, Bocage, Fialho d’Almeida, Frei Luís de Sousa, Almeida Garrett, Carlos Malheiro Dias, Eugénio de Castro, João de Lucena, Pedro Antônio Correia Garção, Pe. Antônio Vieira, Antônio Feliciano de Castilho, Pe. Manuel Bernardes, Nicolau Tolentino de Almeida, Francisco Manoel, Teixeira de Pascoais e outros.

Estudar a língua portuguesa e o uso modelar em escritores ocupava grande parte do tempo dos missivistas. A leitura de dicionário, empreitada já iniciada por Rangel, é também mencionada em carta por Lobato, como exercício formador das respectivas expressões: "Estou lendo e marcando as palavras úteis para o meu caso, os sentidos figurados, aproveitáveis nesta 'nossa' literatura etc. Ainda estou no 'A' e já tenho belos achados. É um verdadeiro mariscar de peneira. Deves fazer a mesma coisa, e depois trocamos as notas". ${ }^{38}$

Outra importante referência na formação de Godofredo Rangel é recuperada em carta de 1910, no SLMG, na qual ele afirma recomeçar seu estudo do português, prosseguindo na quarta leitura de Os Lusíadas, enquanto seu interlocutor admitira não ter conseguido terminá-la após cinco tentativas. ${ }^{39}$

Ambos recorrem aos autores portugueses como meio de aprofundar seu aprendizado da língua. Trocam livros, notas e análises, citam trechos das obras em meio às cartas, propõem planos de estudo e exercícios de escrita. O nome de Camilo Castelo Branco destaca-se na correspondência, dado o encantamento dos epistológrafos por seu estilo literário, citando-se uma variedade de títulos: Onde está a felicidade, Vingança, Anos de prosa, Agulha em palheiro, Amor de salvação, Vinte horas de liteira, Os brilhantes do brasileiro, A mulher fatal, Noites de insônia, O regicida, Novelas do Minho, A caveira da mártir, Eusébio Macário, Cancioneiro alegre de poetas portugueses e brasileiros, $A$ brasileira de Prazins, $O$ vinho do Porto e Boémia do espírito.

$\mathrm{Na}$ carta de 16 de janeiro de 1915, Lobato revela o mecanismo de apropriação de suas leituras e critica o método de estudo de Rangel:

38. Lовато, Monteiro. A barca de Gleyre, cit., p. 207. Carta de Areias, 7 jul. 1909. 39. Idem, p. 106. Carta de Taubaté, 15 mar. 1906. 
$\mathrm{Na}$ tua carta levas ao extremo o estudo camiliano. Levas ao extremo de esfarelá-lo num glossário metodicamente disposto para a rebusca de frases feitas. Condenas aquele meu terreirinho limpo onde caíam as sementes que o vento traz. Com o teu sistema de glossário, sabe o que acontece? Tornamo-nos uns Camilos enfezados, uns puros camelinhos, quando o que eu quero é que de Camilo tu saias mais Rangel do que nunca e eu saia bestialmente Lobato - embora sem as brocas e lagartas para as quais o melhor veneno é justamente Camilo. ${ }^{40}$

Impulsionados a conquistar sua própria expressão ou encontrar-se estilisticamente, os amigos compartilhavam seu modus operandi frente aos estudos e exercícios literários. Lobato vale-se do neologismo "lobatizar" e "rangelizar" para designar a busca de um estilo próprio. ${ }^{41}$ Logo, a leitura torna-se espaço de construção da própria identidade, por meio de uma assimilação vocabular trabalhada.

As divergências metodológicas prosseguem, enquanto a temática do desenvolvimento estilístico é retomada em diferentes cartas. Porém, o afinco em destrinchar o ficcionista de Eusébio Macário acaba por deixar traços na escrita de Rangel. Ao ler o manuscrito de Vida ociosa, Lobato aconselha o amigo a "podar as camilices enxertadas na primeira parte". ${ }^{42}$ A crítica reaparece na carta seguinte, reforçada pela leitura do professor mineiro Adalgiso Pereira, condenando os trechos em que "Camilo está demais" ${ }^{43}$ Éneas Athanázio reconhece também a influência do autor luso na escrita do romance Falange gloriosa, apontando o abuso no descritivo e na caricatura, bem como o uso reiterado de expressões e vocábulos arcaicos e em desuso, mesmo na época em que o livro foi escrito. O biógrafo lista ainda termos presentes no texto de Rangel identificados em Amor de salvação. ${ }^{44}$

Fialho d'Almeida é escritor igualmente estimado pelos correspondentes: "Fialho é um estilo, Rangel! São dois os grandes estilos - Camilo e Fialho".45 Em nove cartas de A barca de Gleyre cita-se o ficcionista português como modelo a ser estudado: "Que

\footnotetext{
40. Idem, p. 297. Carta de Caçapava, 16 jan. 1915.

41. Idem, p. 78. Carta de São Paulo, 15 nov. 1904.

42. Idem, p. 325. Carta de São Paulo, $1^{\circ}$ ago. 1915.

43. Idem, p. 326. Carta de São Paulo, 4 ago. 1915.

44. Athanázio, Enéas. Op. cit., p. 73.

45. LOBAto, Monteiro. Op. cit., p. 407. Carta de Caçapava, 3 out. 1917.
} 
estilo! Bárbaro como um huno, belo como a saúde. Estilo que não dá satisfações a ninguém - que não manda dizer". ${ }^{46}$

O apreço de Rangel pelo prosador lusitano está registrado em "O estilo de Fialho", seu artigo de estreia na Revista do Brasil, em janeiro de 1917. Para Lobato, o autor de A cidade do vício era, como se destacou, dono de um estilo vigoroso, firme; na crítica rangelina aponta-se novamente essa característica da escrita do autor: "traço bem saliente da obra fialhesca, irmão gêmeo do tom categórico, afirmativo, já assinalado, é a liberdade com que diz tudo que quer, cruamente, galegamente, sem eufemismos nem circunlóquios, com a expressão justa, embora porca". ${ }^{47}$

Para estudo da língua, em diferentes cartas, Lobato também indica ao amigo as leituras de Machado de Assis, Euclides da Cunha e Rui Barbosa. ${ }^{4}$ Cabe pontuar que, embora companheiros em busca da formação de seus estilos, o escritor de Emília no país da gramática ainda se vê distante de conquistar a expressão almejada. Encontra em Rangel, entre tantos compartilhamentos que a amizade lhes proporciona, um belo gramático, ${ }^{49}$ alguém que o auxilia nesse caminho, por meio da leitura de seus manuscritos e do apontamento de correções. Ao receber crítica de Adalgiso Pereira, na época revisor da Revista do Brasil, acerca do conto "O engraçado arrependido" (posteriormente lançado no volume Urupês), o taubateano, ainda que humoradamente, não hesita em reconhecer a autoridade de Rangel frente ao exame gramatical de seus textos:

[Adalgiso Pereira] está como revisor da Revista e queixa-se de meus descuidos e deslizes. Vou responder que o meu colocador de pronomes é você, e também o meu mondador de ingramaticalidades; de modo que qualquer queixa contra mim deve ser encaminhada a você, pois assim encurtamos caminho..$^{50}$

46. Idem, p. 310. Carta da Fazenda, 30 mar. 1915.

47. RAngel, Godofredo. "O estilo de Fialho". Revista do Brasil, São Paulo, vol. Iv, n. 13, pp. 53-9, jan. 2017. 48. Em A barca de Gleyre, referências a Machado de Assis: cartas 14 ago. 1909, 30 ago. 1909, 3 jun. 1915, 10 jul. 1916; Euclides da Cunha: 11 set. 1911, 30 set. 1915; Rui Barbosa: 2 jan. 1909, 27 jun. 1909, $1^{\circ}$ jul. 1909, 15 set. 1909. 49. Alusão à carta de 10 de janeiro de 1917 , na qual Lobato recebe resposta de uma dúvida gramatical que o atormenta acerca de uma silepse que lhe "pareceu asneira" no começo de um artigo publicado no jornal O Estado de S. Paulo. LовAтo, Monteiro. Op. cit., p. 387.

50. Idem, p. 394. Carta da Fazenda, 22 abr. 1917. 
Aliás, na carta em questão, Lobato recomenda o envio de exemplar do Estudo prático de Português (1917), ${ }^{51}$ espécie de pequena gramática assinada por Godofredo Rangel, para Adalgiso Pereira. Logo, o empenho do jovem escritor em estudar a língua portuguesa viabiliza, além de exercício para formação estilística, matéria para seu livro abordando assunto gramatical.

\section{ENTRE TANTAS LEITURAS}

Traduzir livros foi outra atividade de Rangel que lhe permitiu ampliar seu repertório de leituras, caminho também trilhado pelo amigo Lobato. O tempo gasto com a tarefa chegou a ser assunto da correspondência entre eles: "Pelo meu setor nada de interesse. Continuo a traduzir. Estou agora roendo um terrível Emile Zola, biografia, de um americano - cousa lenta, para meses".52 No ano seguinte, nove meses após a carta, Rangel reporta-se outra vez ao trabalho na mesma obra: "estou rematando uma tradução e pedindo outra à Editora. Autor dificílimo e que roí - Matthew Josephson, mas que escreveu um livro encantador: Zola e seu tempo".53

Fato é que Rangel assinou mais traduções do que obras de sua autoria. Conseguimos localizar setenta e nove obras traduzidas até o momento da redação deste trabalho. ${ }^{54}$ Optouse apenas por sinalizar a relação de Rangel leitor e tradutor, dados os limites deste trabalho.

51. Segundo nota de Enéas Athanázio, o livro foi lançado em edição particular, feita em Santa Rita do Sapucaí, ficando a impressão a cargo da “Tipografia e Papelaria do Correio do Sul”, encontrandose completamente esgotado. Tinha pouco mais de uma centena de páginas, foi prefaciado pelo prof. dr. Antonio Affonso de Morais e dividia-se em cinco partes que tratavam de ortografia, prosódia, vocabulário, redação e observações gramaticais. ATHAnÁzıo, Enéas. Godofredo Rangel, cit., p. 39.

52. sampaio, Márcio (org.). Op. cit., p. 10. Carta de Belo Horizonte, 12 dez. 1945.

53. Idem, p. 10. Carta de Belo Horizonte, 8 set. 1946.

54. A primeira versão da biografia Godofredo Rangel sinaliza as dificuldades em reunir os títulos traduzidos; na atualização da obra, publicada em 1988, sob o título $O$ amigo escrito, ambas assinadas por Enéas Athanázio, consta um levantamento da tradução de cinquenta e uma obras, com a observação "relação muito incompleta". Assim, consultamos a tese de Célia Luiza Andrade Prado, A tradução na Era Vargas de 1930 a 1940: o Tarzan brasileiro de Manuel Bandeira, Monteiro Lobato e Godofredo Rangel, que se destaca por reunir informações acerca dessa atividade do autor cujo registro é tão escasso. Também nos valemos das teses Práticas de leitura: A Coleção Biblioteca das Moças no Instituto de Educação “Carlos Gomes” em Campinas (1951-1976), de Cássia Aparecida Sales Magalhães Kirchner, e A Coleção Bibliotheca do Espírito Moderno: um projeto para alimentar espíritos da Companhia Editora Nacional (1938-1977), de Sílvia Asam da Fonseca, a fim de rastrear os títulos traduzidos por Rangel para essas coleções da Companhia Editora Nacional. Além disso, buscamos referências no Banco de Dados Bibliográficos da Universidade de São Paulo e no Sistema de Bibliotecas da Unicamp. 
Outra possibilidade ainda é valer-se da correspondência como arquivo da literatura, em que críticos voyeurs, segundo José-Luis Diaz, ${ }^{55}$ podem acompanhar os diversos estados de criação de uma obra. Rangel e Lobato foram grandes leitores entre si, compartilhavam seus manuscritos, trocavam impressões acerca da criação, testemunhando-se a gênese (muitas vezes a quatro mãos) e os vestígios de etapas do processo de criação. Está guardado na correspondência o "canteiro" de diversas obras de ambos os escritores.

Enfim, diante de tantos registros de leituras, é possível afirmar que Godofredo Rangel leitor desdobra-se pela literatura em diferentes momentos e perfis, seja em sua própria formação e trajetória como leitor e escritor e, até mesmo, nos ofícios de professor e tradutor. Para este trabalho, estabeleceu-se apenas um breve recorte de algumas das principais referências deixadas ao longo da correspondência, assinalada a importância da literatura na vida dos amigos escritos que compartilhavam "o carnegão literário", como brinca Lobato. ${ }^{56}$ Cabe ressaltar que a relação de Rangel com a literatura oferece um rico manancial de possibilidades para outras pesquisas se aprofundarem.

Camila Russo de Almeida Spagnoli é doutoranda no Programa de pós-graduação em Literatura Brasileira (bolsista CNPq), na Universidade de São Paulo.

55. DIAZ, José-Luis. “Qual genética para as correspondências?”. Trad. Cláudio Hiro e Maria Sílvia Ianni Brasalini. Manuscrítica. Revista de Crítica Genética, São Paulo: Humanitas, n. 15, p. 123, 2007. 56. LовAтo, Monteiro. Op. cit., p. 64. Carta de São Paulo, 16 jun. 1904. 